\title{
Associations and Experiences Observed for Family and Nonfamily Forms of Violent Behavior in Different Relational Contexts Among Swedish Men and Women
}

\author{
Johanna Simmons, Barbro Wijma and Katarina Swahnberg
}

\section{Linköping University Post Print}

\section{Tweet}

N.B.: When citing this work, cite the original article.

The original publication is available at www.springerlink.com:

Johanna Simmons, Barbro Wijma and Katarina Swahnberg, Associations and Experiences Observed for Family and Nonfamily Forms of Violent Behavior in Different Relational Contexts Among Swedish Men and Women, 2014, Violence and Victims, (29), 1, 152-170. http://dx.doi.org/10.1891/0886-6708.VV-D-12-00084

Copyright: Springer Publishing Co

http://www.springerlink.com/?MUD=MP

Postprint available at: Linköping University Electronic Press

http://urn.kb.se/resolve?urn=urn:nbn:se:liu:diva-105043 
Associations and Experiences Observed for Family and Non-Family Forms of Violent Behavior in Different Relational Contexts among Swedish Men and Women

\section{Johanna Simmons, MD}

Division of Gender and Medicine, Department of Clinical and Experimental Medicine, Linköping University, Department of Acute Internal Medicine, County Council of Östergötland, Linköping, Sweden

\section{Barbro Wijma, Professor, MD}

Division of Gender and Medicine, Department of Clinical and Experimental Medicine, Linköping University, Sweden.

\section{Katarina Swahnberg, PhD, MPH}

Division of Gender and Medicine, Department of Clinical and Experimental Medicine, Linköping University, Sweden.

Department of Health and Caring Sciences, Faculty of Health and Life Sciences, Linnaeus University

Corresponding author: Johanna Simmons, Div of Gender and Medicine, Dept of Clinical and Experimental Medicine, Linköping University, S-581 83 Linköping, Sweden. Phone number: +46 101032089. E-mail: johanna.simmons@liu.se

Acknowledgments: The NorVold Abuse Questionnarie (NorAQ) was developed by NorVold, a research network established in 1997 to explore the prevalence of violence against women and its effects on women's health. The NorVold research network was supported by grants from the Nordic Council of Ministers.

Principal investigators: Barbro Wijma, Berit Schei

Coordinator: Katarina Swahnberg 
Local investigators: Denmark: Katrine Sidenius, Malene Hilden, Finland: Erja Halmesmäki, Ulla Pikkarinen, Iceland: Tora Steingrimsdottir, Norway: Berit Schei, Hildegunn Stoum-

Hinsverk, Kristin Offerdal, Sweden: Barbro Wijma, Katarina Swahnberg 


\title{
Associations and Experiences Observed for Family and Nonfamily Forms of Violent Behavior in Different Relational Contexts Among Swedish Men and Women
}

\begin{abstract}
The aim of the present study was to examine how lifetime experiences of different types of violent behavior as well as violence by different kinds of perpetrators overlap, and to investigate the co-occurrence of experiences of violent behavior by kind of perpetrator. This was done among both sexes in both a random sample from a county population (women $\mathrm{n}=1168$, men $\mathrm{n}=2924$ ) and a clinical sample (women $\mathrm{n}=2439$, men=1767) in Sweden. More than one kind of perpetrator was reported by $33-37 \%$ of female and $22-23 \%$ of male victims of some kind of violence, whereas $47-48 \%$ of female and $29-31 \%$ of male victims reported more than one kind of violence. The reporting of two or three kinds of perpetrators was associated with the reporting of experiences of more than one kind of violent behavior. Health care providers must be trained to recognize the overlap of violent victimization and help prevent further victimization of those who already have such experiences.
\end{abstract}

Keywords: Re-victimization, Gender, Cumulative violence, Perpetrator, Multiple victimization 


\section{Associations and Experiences Observed for Family and Non-Family Forms of Violent Behavior in Different Relational Contexts among Swedish Men and Women}

\section{Background}

Many victims of violence are subjected to more than one kind of violent behavior (e.g., physical, sexual or emotional) and/or violence from more than one kind of perpetrator (e.g., family members, intimate partners or peers) during their lifetime (Tjaden and Thoennes 2000; Coid, Petruckevitch, Feder, Chung, Richardson and Moorey 2001; Desai, Arias, Thompson and Basile 2002; Romito and Grassi 2007; Widom, Czaja and Dutton 2008; Scott-Storey 2011). Researchers have focused on different aspects of this cumulative victimization and hence, different, but related concepts evolved. On the one hand, poly-victimization is mainly used in research on violence in childhood and adolescence, and is most commonly defined as experiencing four or more different kinds of victimization in one year. Re-victimization, on the other hand, describes violent victimization across different developmental periods, mainly childhood and adulthood (Daigle, Fisher and Cullen 2008). In this article, associations between lifetime experiences of different kinds of violent behavior as well as violence in different relational contexts will be described, regardless of age at victimization. Hence our study is closely related to both the earlier-mentioned concepts, but neither of them are perfectly suited.

Finkelhor and colleagues introduced the concept of poly-victimization in research on child and adolescent victimization (Finkelhor, Ormrod and Turner 2007). It is based on the number of violent experiences a victim has had, and various events are included in the concept, for example: bullying, experiencing crimes such as robbery and child maltreatment, and witnessing as well as experiencing physical and sexual violence both from adults or peers. Counting the number of violent events in this way has turned out to be a strong predictor of 
subsequent victimization, and has repeatedly been shown to correlate with poor health outcomes beyond what could be explained by the individual types of victimization (Finkelhor, Ormrod and Turner 2007; Gustafsson, Nilsson and Svedin 2009). When conceptualizing polyvictimization, Finkelhor underlines that is not merely about the repetition of violent events; rather, violence has become an ongoing condition for victims (Finkelhor et al. 2007).

The concept of re-victimization evolved from studies of sexual re-victimization among women, that is, suffering from childhood sexual abuse and later in life being subjected to rape or other kinds of sexual violence (Messman-Moore and Long 2003). Over the years, the field has expanded to include physical and to some extent emotional violence. Men were included in some studies (Arata 2000; Coid et al. 2001; Kimerling, Alvarez, Pavao, Kaminski and Baumrind 2007; Widom et al. 2008; Aosved, Long and Voller 2011; Parks, Kim, Day, Garza and Larkby 2011). For women, a graded relationship was reported, as experiencing multiple forms of childhood victimization results in a higher likelihood of both adult rape by any perpetrator and intimate partner violence (Whitfield, Anda, Dube and Felitti 2003; MessmanMoore and Brown 2004; Cloitre and Rosenberg 2006). The primary focus in studies of revictimization is violence across developmental periods, and consequently it is not always explicit who the perpetrator was, or analyses may not be separated by kind of perpetrator. (Coid et al. 2001; Desai et al. 2002; Widom et al. 2008; Cloitre, Stolbach, Herman, van der Kolk, Pynoos, Wang and Petkova 2009; Parks et al. 2011).

A number of studies on re-victimization does consider the relational context of adult victimization, for example, those that have found strong associations between women's experiences of different kinds of childhood abuse and intimate partner violence in adulthood (Coid et al. 2001; Desai et al. 2002; Whitfield et al. 2003; Rich, Gidycz, Warkentin, Loh and Weiland 2005; McKinney, Caetano, Ramisetty-Mikler and Nelson 2009; Renner and Whitney 2012). Contradictory findings exist for men. McKinney and colleagues report associations 
between childhood family violence and victimization by an intimate partner while Desai and colleagues did not find this (Desai et al. 2002; McKinney et al. 2009). For women, experiences of childhood abuse have also been found to increase the risk of being repeatedly victimized by different intimate partners (Cole, Logan and Shannon 2008; Alexander 2009). Associations between childhood abuse and adult victimization by non-partners have been found for both sexes, especially sexual re-victimization by any perpetrator (Tjaden and Thoennes 2000; Coid et al. 2001; Desai et al. 2002). Evidence also supports that childhood physical abuse and neglect is linked to adult victimization by non-partners for both sexes (Desai et al. 2002; Arias 2004; Romito and Grassi 2007; Widom et al. 2008). In the U.S National Survey of Violence Against Women (NSVAW), both men and women who had been physically abused by a caregiver in childhood were twice as likely to be physically assaulted in adulthood by any perpetrator. Rape re-victimization by any perpetrator as well as stalking re-victimization by any perpetrator was also found among women. The numbers of male rape victims and male victims of stalking were too small to make meaningful analyses of revictimization (Tjaden and Thoennes 2000).

A theoretical framework for understanding re-victimization has primarily evolved from studies of sexual violence against women, but it is also being used to understand other kinds of re-victimization (Messman-Moore and Long 2003; Cloitre and Rosenberg 2006; Alexander 2009). Childhood abuse is likely to affect victims' developmental processes. Difficulties in affect regulation could be a consequence, including dissociation and lowered risk recognition, which may render victims more susceptible to re-victimization (Cloitre and Rosenberg 2006). Abuse is also theorized to alter interpersonal schemas. Victims may develop distorted beliefs about themselves and the surrounding world, resulting in a high expectancy and acceptance of negative, abusive behavior from people in their vicinity (Jehu 1988; Cloitre and Rosenberg 2006; Alexander 2009; Cloitre et al. 2009). Other consequences of abuse such as feelings of 
shame, depression, PTSD and altered behavior including substance abuse, have been put forward as risk factors for re-victimization (Arata 2000; Messman-Moore and Long 2003; Cloitre and Rosenberg 2006). However, it is important to keep in mind that re-victimization is not an intrapersonal but an interpersonal process. The earlier-mentioned risk factors are only risk factors in relation to perpetrators who take advantage of a victims vulnerability (Messman-Moore and Long 2003).

Whether or not the kind of perpetrator is considered, it is clear that re-victimization is an important subject; childhood and adult victimization tend to co-occur. Victimization is not randomly distributed within the population (Cloitre and Rosenberg 2006; Kimerling et al. 2007).

Though not as well investigated, associations were also found between different kinds of victimization in adulthood for both sexes. Intimate partner violence is associated with violence from acquaintances, strangers or co-workers in youth and adulthood (Porcerelli, Cogan, West, Rose, Lambrecht, Wilson, Severson and Karana 2003; Romito, Molzan Turan and De Marchi 2005; Taylor, Boris, Heller, Clum, Rice and Zeanah 2008; Montero, RuizPerez, Martin-Baena, Talavera, Escriba-Aguir and Vives-Cases 2011). It is also known that many women subjected to intimate partner violence were victimized by more than one partner (Cole et al. 2008; Alexander 2009). Repeat sexual and physical victimization was found among college women, and interestingly, repeat victimization was primarily found in the month following the initial victimization (Daigle et al. 2008)

Though the number of studies including men has increased over the years, less is known about male than female re-victimization (Aosved et al. 2011). Male victimization in intimate partner relationships has received increased attention over the years. Some studies report gender symmetry, that is, that men and women are equally likely to be the victim of intimate 
partner violence (Archer 2000). However, the characteristics and consequences of violence were shown to be more severe for women and the argument was given that violence differs conceptually between the sexes (Kimmel 2002; Cercone, Beach and Arias 2005; Johnson 2008). This highlights a need for a gendered analysis of victimization.

Taken together, it is evident from previous research that victims of violence have a tendency to be victimized again. However, the victim-perpetrator relationship is not always considered. To date, research on violent victimization in Sweden has mainly focused either on childhood abuse or intimate partner violence. The prevalence of life-time emotional, physical and sexual violence among both men and women has been studied before (Wijma, Schei, Swahnberg, Hilden, Offerdal, Pikarinen, Sidenius, Steingrimsdottir, Stoum and Halmesmaki 2003; Swahnberg, Wijma, Schei, Hilden, Irminger and Wingren 2004; Swahnberg, Hearn and Wijma 2009; Swahnberg, Davidsson-Simmons, Hearn and Wijma 2012) However, knowledge about the co-occurrence of violent victimization is scarce, and as far as we know, studies on associations between lifetime violent victimization of men and women by different kinds of perpetrators have not previously been investigated in Sweden. Most of the studies reviewed previously were conducted in the U.S. Though we expect to find analogous results, it cannot be assumed that the prevalence and overlap of violent victimization is similar between nations and across cultural borders. Our study contributes to the existing knowledge by investigating violent victimization in a different setting from what has been done before.

Aim: Among both sexes, in a random population sample and in a clinical sample, we aim to examine: 1) how experiences of different types of violent behavior (i.e., physical, sexual and emotional violence) overlap 2) how violence by different perpetrators (i.e., family members, intimate partners and acquaintance or strangers) overlap and 3) the co-occurrence of reported violent behavior by kind of perpetrator. 


\section{Method}

The present study is based on a secondary analysis of data previously collected for prevalence studies of violence against women and men in Sweden (Wijma et al. 2003; Swahnberg et al. 2004; Swahnberg et al. 2009; Swahnberg et al. 2012). Detailed descriptions of the procedure for all data collections were published previously. For this study, four original samples were used. One female sample $(n=1168$ response rate $=61 \%)$ and one male sample $(n=2924$, response rate $=50 \%$ ) were taken at random from the population of the county of Östergötland, Sweden, in 2000 and 2007 respectively. These two samples will be referred to as the population sample. A female sample was also taken from gynecology clinics at three different hospitals in $2000(\mathrm{n}=2439$, response rate $=81 \%)$. In 2005, six somatic clinics were used for a male sample of 1767 respondents (response rate $=75 \%$ ). These two samples will be referred to as the clinical sample.

Data was collected with the male and female versions of the NorVold Abuse Questionnaire, henceforth collectively referred to as NorAQ. NorAQ was tested in both male and female samples and the test-retest reliability for the abuse questions ranged from $84-95 \%$ among women and 77-100\% among men. The positive likelihood ratio among women was 38 for emotional violence, 42 for sexual violence and 6 for physical violence. Among men the positive likelihood ratio was lower: 3 for emotional violence, 46 for sexual violence and 9 for physical violence (Swahnberg and Wijma 2003; Swahnberg 2011). The question covering mild physical violence had considerably lower concurrent validity than the other questions. For this reason, those who answered yes to that question, but no to the subsequent questions about moderate and/or severe physical violence, were considered as non-victims of physical violence. NorAQ covers lifetime experiences of emotional, sexual and physical violence. Background characteristics such as age, occupation, education and civil status are also addressed. The questions used to operationalize violent victimization are presented in table 1. 
[Insert table 1]

Due to the structure of NorAQ, the reported perpetrator could only be related to the kind, not to the severity, of violent behavior. The different degrees of severity of violence were therefore merged and coded into one variable with the following categories: a) No violence b) Emotional c) Physical d) Sexual e) Emotional and physical f) Emotional and sexual g) Physical and sexual h) Emotional, physical and sexual.

Respondents were asked about the person who subjected them to violence and they had the option of giving several answers for each kind of violence. The answers were then grouped together depending on the reported relationship between the victim and the perpetrator. Reporting parents, stepparents and/or siblings as perpetrator was coded as family perpetrator, while a former or present partner perpetrator was coded as partner perpetrator. "Same age playmate, schoolmate or other person under 18”, “a known person who doesn't belong to your family", "a person totally unknown to you" and "other" was coded as acquaintance/stranger perpetrator. Finally, the answers were grouped into one variable with the following mutually exclusive categories describing the kind of perpetrator reported: a) No violence b) Family c) Partner d) Acquaintances/Strangers e) Family and partner f) Family and Acquaintance/ stranger g) Partner and acquaintance/stranger h) Family, partner and acquaintance/stranger. Statistical analyses

The statistical program SPSS, version 20, was used to compute all analyses. Pearson's chisquared test was used to test for differences in background characteristics between the sexes in both samples (table 2). Descriptive statistics were used to examine the overlap of reported types of violent behavior as well as the overlap of reported perpetrator (figure 1) and the cooccurrence of violent behavior by kind of perpetrator (figure 2). 
To test for associations between violence from different kinds of perpetrators, three two-step hierarchal binary logistic regression analyses were used. These were calculated separately for each of the four samples. 1. In the first model, experiences of partner violence, yes or no was put as the dependent variable. 1A. Because the samples differed significantly on background characteristics (age, civil status, occupation and education), these were put as independent variables in the first step $1 \mathrm{~B}$. In the second step a perpetrator variable with the following answering alternatives were put as independent variables: a) no violence from family members or acquaintances/strangers b) violence from a family perpetrator c) violence from acquaintance/stranger perpetrator and d) violence from both family and acquaintance/stranger perpetrators. 2. In the second model, experiences of family violence (yes or no) was put as the dependent variable. 2A. Background characteristics were again entered as independents in the first step. 2B. In the second step, reporting violence from a) no other perpetrator b) intimate partner c) acquaintances/strangers and d) intimate partner and acquaintances/strangers were put as an independent variable. 3. In the third model, reporting violence from acquaintances/strangers (yes or no) was put as dependent variable. 3A. Background characteristics were put as independents in the first step. 3B. Violence from other kinds of perpetrators was put as an independent variable in the second step.

\section{Ethical considerations}

Considering the sensitivity of the subject, it might have been uncomfortable for some participants to answer the questions in NorAQ. An invitation to contact either the research team or a therapist was therefore included in the material sent to respondents. This possibility was used by few. All data collection was approved by the regional ethical review board.

\section{Results}


Background characteristics for the samples are shown in table 2. Statistically significant differences were found between men and women in both the clinical sample and the population sample. In both samples, men were more frequently single and they were overrepresented in the category of respondents over the age of 60 (table 2). In the clinical sample especially, the men were considerably older than the women, and more likely to be retired or on sick leave. In the population sample, men were more likely to be employed than women (table 2).

[Insert Table 2]

In total, more men (population sample $42 \%$; clinical sample 35\%) than women (population sample $36 \%$; clinical sample $33 \%$ ) answered yes to at least one of the questions covering violent experiences. As shown in figure 1, female victims were more likely to report experiences of two or three kinds of violent behavior (population sample: women $47 \%$, men $31 \%$; clinical sample: women $48 \%$, men $29 \%$ ). In both samples, men were more likely to report physical violence and the combination emotional and physical violence, while women were overrepresented in all other forms and combinations of violent behavior (figure 1).

\section{[Insert figure 1]}

Likewise, in the population sample, $37 \%$ of female victims and $22 \%$ of male victims reported violence from more than one kind of perpetrator. In the clinical sample, the corresponding figure for female victims was $33 \%$ and for male victims $23 \%$ (figure 1). Emotional violence was reported in all relational contexts, and the reporting of experiences of two or three kinds of violent behavior was more common among those reporting two or three kinds of perpetrators than those only reporting one kind of perpetrator. More details on the cooccurrence of violent behavior (e.g., physical, sexual and emotional) by kind of perpetrator (e.g., family member, intimate partner and acquaintance/stranger) can be found in figure 2 . 
[Insert figure 2]

Victims of both sexes reporting family violence had increased odds of also reporting partner violence (population sample: men adj OR $=5.1,95 \%$ CI 2.5-10.5, women adj OR 4.4, 95\% CI 2.6-7.3; clinical sample: men adj $\mathrm{OR}=4.8,95 \% \mathrm{CI} 1.5-15.3$, women adj OR 2.8, 95\% CI 1.9-4.1). In both samples and among both sexes, victims reporting acquaintance/stranger violence had three times the odds of also reporting partner violence, while experiences of both family violence and violence from acquaintances/strangers increased the odds for reporting partner violence even further (population sample: men adj OR $=9.7,95 \%$ CI 5.9-16.1, women adj OR 6.1 95\% CI 3.6-10.2; clinical sample: men adj OR = 6.3, 95\% CI 2.6-15.2, women adj OR 6.8, 95\% CI 4.6-10.2). A similar pattern was found for reporting violence from the other kinds of perpetrators. For details please see table 3.

[Insert table 3]

\section{Discussion}

In this study, more than every third female victim and more than every fifth male victim reported violence from more than one kind of perpetrator. Experiences of more than one kind of violent behavior were reported by almost half of the female victims and almost one third of the male victims (figure 1). For both sexes, strong associations were found between the reporting of violence from all different kinds of perpetrators (table 3).

\section{The overlap of violent victimization}

Differences in the definitions and the operationalization of violent victimization, as well as different categorizations of perpetrators, are found in studies on violence. This creates difficulties in making meaningful comparisons between studies. However, our results confirm previous findings of a substantial overlap between different kinds of violent behaviors and/or 
victimization by different perpetrators. Romito found that more than half of both male and female victims report experiences of more than one kind of violent behavior, and though limited to victimization during the past year, Porcerelli found that more than every fourth victim of both sexes reported violence by more than one kind of perpetrator (Porcerelli et al. 2003; Romito and Grassi 2007).

Reporting two perpetrators was found to have an amplifying effect on the odds of reporting also the third kind of perpetrator. This held true for violence from all kinds of perpetrators, in both samples and for both sexes (table 3). Reporting two or three kinds of perpetrators was associated with experiences of more than one kind of violent behavior (figure 2). This result can be related to previous research finding: a graded relationship between reporting multiple forms of childhood violence and the risk of reporting adult victimization (Whitfield et al. 2003; Cloitre and Rosenberg 2006).

Though we do not know the age at victimization in this study, it is reasonable to assume that much of the violence perpetrated by a family member occurred in childhood while partner violence occurred during youth or adulthood. Hence, our results support previous findings in studies of re-victimization, namely the associations between childhood abuse by a caregiver and intimate partner violence, as well as in studies showing associations between childhood and adult abuse by any perpetrator (Tjaden and Thoennes 2000; Coid et al. 2001; Alexander 2009; McKinney et al. 2009).

In many studies of re-victimization, childhood sexual abuse is operationalized as sexual contact by a relative, or by an individual more than 5 years older, or sexual contact with a peer that involved threat of or actual physical violence. Though not always the case, these three kinds of sexual violence are sometimes merged and analyzed as one. Regarding childhood physical/emotional violence, it is common that only questions about violence 
perpetrated by a caregiver are asked (Coid et al. 2001; Desai et al. 2002; Whitfield et al. 2003; Rich et al. 2005; Aosved et al. 2011). Though this makes sense in many ways, it is also problematic, because it excludes physical/emotional violence in childhood by other perpetrators than caregivers, and this puts childhood sexual violence by a relative and any other perpetrators on an equal footing. Childhood sexual abuse by family members have higher odds of resulting in re-victimization than abuse by other adults or peers (Cloitre and Rosenberg 2006). Generally, violence in more intimate relationships, such as within the family or between partners, has the strongest impact on victims (Haynie, Petts, Maimon and Piquero 2009). In this study we did not measure the outcome of victimization; however, previous research indicates that victimization by perpetrators other than family members and partners also have consequences for victims. Exposure to community violence in young adults has been linked to depression, aggressive behavior, symptoms of PTSD and interpersonal problems (Scarpa 2003). Sexual assault by a friend or acquaintance is associated with increased involvement in risky behaviors, as is assault by multiple perpetrators (Davis, Combs-Lane and Jackson 2002). Victimization in adulthood by acquaintances/strangers has received less attention than intimate partner violence. Though this is reasonable, it should be noted that we found violence perpetrated by acquaintances/strangers to be more common than intimate partner violence for both men and women (figure 1). The same was found in a previous study of college women (Daigle et al. 2008). For both sexes, in our study, lifetime experiences of victimization by acquaintances/strangers were strong predictors for victimization by other perpetrators (table 3). Previously, for both sexes, physical and/or sexual abuse in childhood by any perpetrator has been found to predict both physical and sexual adult victimization by non-partners (Desai et al. 2002).

Studies of poly-victimization in childhood highlight the importance of victimization in multiple contexts. Putting the theoretical framework of re-victimization together with theories 
of poly-victimization might be interesting. Finkelhor describes poly-victimization as a state where victimization is no longer considered a part of separate events; it has rather become a condition (Finkelhor et al. 2007). It could be interesting to add this perspective to an ecological model of re-victimization, as suggested by Messman-More and Long, and also include violence from acquaintances/strangers (Heise 1998; Messman-Moore and Long 2003).

\section{Sex differences}

Physical violence was more common among male victims than among female victims, while female victims more commonly reported sexual violence than male victims. Emotional violence was more equally distributed between the sexes (figure 1). More than one kind of violence and experiences of violence from more than one perpetrator was more commonly reported by women than men, which could be interpreted as indicators of a heavier burden of violence (figure 1). All of this confirms previous findings (Tjaden and Thoennes 2000; Baker, Norris, Diaz, Perilla, Murphy and Hill 2005; Romito and Grassi 2007).

Emotional violence is generally discussed in terms of partner violence or childhood family abuse. However, when studying figure 2, it becomes clear that emotional violence from other kinds of perpetrators is also often reported. In the present study, male victims more often reported emotional violence from both family and acquaintances/strangers than from partners. Among female victims, the reported perpetrator of emotional violence was almost equally distributed among family, partner and acquaintances/strangers perpetrators (figure 2). It would be of interest to study emotional violence more closely, to get a better understanding of what it implies in relationship contexts other than between intimate partners, and if the meaning of emotional violence is different for men and women. 
Women reported victimization by a family perpetrator slightly more often (figure 1), while, confirming previous studies, men reported more violence by acquaintances/strangers (figure 1). We did not find gender symmetry for partner violence. On the contrary, in the population sample women reported partner violence three times more often than did men and in the clinical sample six times more often. Gender symmetry is primarily found in studies using the Conflict Tactic Scale (CTS), and NorAQ differs markedly from the CTS because it does not situate violence as occurring in partner relationships; rather, questions are asked about violent behaviors and respondents are given a list of potential perpetrators. Two Swedish studies of intimate partner violence against both men and women have recently been published. In one, the CTS was used and men were found to report higher levels of physical, and women higher levels of sexual victimization in the previous year (Lovestad and Krantz 2012). In the other, using the WHO's Violence Against Women instrument, similar prevalence rates were found for the sexes regarding victimization in the previous year (Nybergh, Taft, Enander and Krantz 2013). In both studies however, the earlier in life prevalence of intimate partner violence was higher among women than men. This supports our finding that lifetime victimization by an intimate partner is more common among women than men in Sweden and contradicts the idea of gender symmetry in intimate partner victimization.

The sex differences in victimization found in this study and in previous research underline that men and women have different experiences of violence. As a result, the consequences of victimization are likely to be different, not only on an individual level but also between the sexes. However, simplifying matters too much and portraying men as perpetrators and women as victims of violence might minimize the existence and consequences of violence against men. Although gender is an essential factor when conceptualizing the nature of violence, an even more fruitful approach to understanding and intervening against interpersonal violence might be to analyze it within the context of not only gender, but also of other power relations, 
such as class, ethnicity and sexuality (Stanko 2006). It is a limitation to our study that we were not able to do this.

\section{Methodological considerations}

Widespread kinds of childhood abuse, such as neglect and the witnessing of parental aggression are not included in the present study. This is unfortunate, because both these kinds of victimization are found to be strong predictors for victimization in partner relationships in adult life (McKinney et al. 2009; Renner and Whitney 2012)

Another limitation is that measurements of the psychological sequel of victimization, such as suffering, dissociation, or posttraumatic stress symptoms were not included in the present study. If such information had been available we might have been able to contribute to the understanding of why victims of violence are victimized again by different perpetrators, and perhaps also to describe the overlap of victimization.

In the present study, all degrees of severity were merged for each kind of violence. Hence, each kind of violence constitutes a very broad spectrum of experiences. We also grouped perpetrators together into only three categories (table 2). Though this merging of groups had its drawbacks, considering that we lost valuable information and variation, it was done to capture the focal point of the present study. Our aim was not to measure the prevalence of different kinds of violence; rather, we wanted to investigate associations between experiences of different kinds of violent behavior and between violence from different kinds of perpetrators.

Due to the structure of NorAQ, it was only possible to match the reported perpetrator with the kind of violent behavior, not with the age at victimization. This was unfortunate. However, although analyzing the relationship between violence in childhood and violence in adult life is an extremely valid and important task, analyzing violence in different relational contexts as 
we have done is also of interest, and this shift in perspective might add something to the existing knowledge. For the two samples used in this study, the distribution of childhood and adult victimization, as well as the prevalence of mild, moderate and severe violence was published previously (Wijma et al. 2003; Swahnberg et al. 2004; Swahnberg et al. 2009; Swahnberg et al. 2012).

Because the question on mild physical violence was excluded from the present study, there is a risk that respondents reporting two or more perpetrators of physical violence are overestimated. For example, if a respondent had experiences of mild physical violence from a parent and moderate physical violence from an acquaintance he or she would be coded as having experiences of physical violence by both parent and acquaintance even though he or she more accurately should be placed among those reporting physical violence only by an acquaintance. However, because the question on mild physical violence did not have satisfactory psychometric properties, we judged it to be better to exclude this variable despite the earlier-mentioned risk.

It should be pointed out that this article underestimates the number of respondents subjected to violence from more than one kind of perpetrator, since NorAQ only measures the kind of perpetrator, not the number of perpetrators. For example, someone reporting an "ex-partner" as a perpetrator might have experienced violence from one partner once or from every partner he or she has ever had. However, this weakness only further emphasizes a need to consider victimization from several perpetrators as an important phenomenon when studying interpersonal violence.

The cross-sectional retrospective design is a limitation, because it is not possible to know the temporal sequence of the different kinds of victimization and because re-call bias may be an issue. It is not unlikely that especially the older respondents didn't recall violence that they 
had been subjected to as children or young adults. The men in the clinical sample were considerably older than the rest of the respondents, and hence we might have underestimated the prevalence of violence in this sample. This might be one of the explanations for why the men in the population sample reported some kind of victimization almost $8 \%$ more often than men in the clinical sample did. In the population sample we had a response rate of $61 \%$ among women and 50\% among men. In the clinical sample the response rate was $81 \%$ among women and $75 \%$ among men. The rather low response rate in the population sample is of concern for the generalizability of our results. It is also potentially problematic that data was collected at different periods in time: the first in 1999 and the last in 2007. Societal changes might have occurred in this time frame, affecting the rates of violent victimization. However, since we measure lifetime experiences of violence, this is not likely to have a major effect on results. Also, our main focus is on associations between different kinds of violent victimization, not on prevalence. The patterns of the co-occurrence of violence are similar across our samples (figures 1-2), which is an indication that the results hold true despite partially low response rates and the years that passed between data collections.

Conclusion: Lifetime experiences of different kinds of violent behavior and violence from different kinds of perpetrators tend to overlap considerably. This is an important finding for both primary and secondary preventions of violence. Health care providers need to be aware of this and should be trained to recognize the overlap of violent victimization, so as to help victims in the best possible way.

\section{References}

Alexander, P. C. (2009). "Childhood Trauma, Attachment, and Abuse by Multiple Partners." Psychological Trauma: Theory, Reserach, Practice and Policy 1(1): 78-88.

Aosved, A. C., P. J. Long and E. K. Voller (2011). "Sexual revictimzation and adjustment in college men." Psychology of Men \& Masculinity 12(3): 285-296.

Arata, C. M. (2000). "From child victim to adult victim: a model for predicting sexual revictimization." Child Maltreat 5(1): 28-38. 
Archer, J. (2000). "Sex differences in aggression between heterosexual partners: a meta-analytic review." Psychol Bull 126(5): 651-680.

Arias, I. (2004). "The legacy of child maltreatment: long-term health consequences for women." J Womens Health (Larchmt) 13(5): 468-473.

Baker, C. K., F. H. Norris, D. M. V. Diaz, J. L. Perilla, A. D. Murphy and E. G. Hill (2005). "Violence and PTSD in Mexico. Gender and regional differences." Soc Psychiatry Psychiatr epidemiol 40: $519-528$.

Cercone, J. J., S. R. Beach and I. Arias (2005). "Gender symmetry in dating intimate partner violence: does similar behavior imply similar constructs?" Violence Vict 20 (2): 207-218.

Chow, S. and P. Rodgers. (2005). Extended Abstract: Constructing Area-Proportional Venn and Euler Diagrams with Three Circles. Euler Diagrams Workshop. Paris.

Cloitre, M. and A. Rosenberg (2006). Sexual revictimization. Risk factors and prevention. CognitiveBehavioral Therapies for Trauma. V. C. Follette and J. I. Ruzek. New York, The Guilford Press: 321-361.

Cloitre, M., B. C. Stolbach, J. L. Herman, B. van der Kolk, R. Pynoos, J. Wang and E. Petkova (2009). "A developmental approach to complex PTSD: childhood and adult cumulative trauma as predictors of symptom complexity." J Trauma Stress 22(5): 399-408.

Coid, J., A. Petruckevitch, G. Feder, W.-S. Chung, J. Richardson and S. Moorey (2001). "Relation between childhood sexual and physical abuse and risk of revictimisation in women: A crosssectional survey." Lancet 358: 450-454.

Cole, J., T. K. Logan and L. Shannon (2008). "Women's risk for revictimization by a new abusive partner: for what should we be looking?" Violence Vict 23(3): 315-330.

Daigle, L. E., B. S. Fisher and F. T. Cullen (2008). "The violent and sexual victimization of college women: is repeat victimization a problem?" J Interpers Violence 23(9): 1296-1313.

Davis, J. J., A. M. Combs-Lane and T. L. Jackson (2002). "Risky Behaviors Associated With Interpersonal Victimization : Comparisons Based on Type, Number, and Characteristics of Assault Incidents." Journal of Interpersonal Violence 17: 611-629.

Desai, S., I. Arias, M. P. Thompson and K. C. Basile (2002). "Childhood victimization and subsequent adult revictimization assessed in a nationally representative sample of women and men." Violence Vict 17(6): 639-653.

Finkelhor, D., R. K. Ormrod and H. A. Turner (2007). "Poly-victimization: a neglected component in child victimization." Child Abuse Negl 31(1): 7-26.

Finkelhor, D., R. K. Ormrod and H. A. Turner (2007). "Re-victimization patterns in a national longitudinal sample of children and youth." Child Abuse Negl 31(5): 479-502.

Gustafsson, P. E., D. Nilsson and C. G. Svedin (2009). "Polytraumatization and psychological symptoms in children and adolescents." Eur Child Adolesc Psychiatry 18(5): 274-283.

Haynie, D. L., R. J. Petts, D. Maimon and A. R. Piquero (2009). "Exposure to violence in adolescence and precocious role exits." J Youth Adolesc 38(3): 269-286.

Heise, L. L. (1998). "Violence against women: An integrated, ecological framework." Violence against women $4(3)$.

Jehu, D. (1988). Beyond Sexual Abuse Therapy With Women Who Were Childhood Victims, John Wiley \& Sons Ltd.

Johnson, M. P. (2008). A typology of violence: intimate terrorism, violent resistance and situational couple violence. . Boston, Northeastern university press.

Kimerling, R., J. Alvarez, J. Pavao, A. Kaminski and N. Baumrind (2007). "Epidemiology and consequences of women's revictimization." Womens Health Issues 17(2): 101-106.

Kimmel, M. S. (2002). "Gender symmetry in domestic violence: a substantive and methodological research review." Violence Against Women, Special Issue: Women's Use of Violence in Intimate Relationships, Part 1 8(1): 1332-1363.

Lovestad, S. and G. Krantz (2012). "Men's and women's exposure and perpetration of partner violence: an epidemiological study from Sweden." BMC Public Health 12: 945.

McKinney, C. M., R. Caetano, S. Ramisetty-Mikler and S. Nelson (2009). "Childhood family violence and perpetration and victimization of intimate partner violence: findings from a national population-based study of couples." Ann Epidemiol 19(1): 25-32. 
Messman-Moore, T. L. and A. L. Brown (2004). "Child maltreatment and perceived family environment as risk factors for adult rape: is child sexual abuse the most salient experience?" Child Abuse Negl 28(10): 1019-1034.

Messman-Moore, T. L. and P. J. Long (2003). "The role of childhood sexual abuse sequelae in the sexual revictimization of women: an empirical review and theoretical reformulation." Clin Psychol Rev 23(4): 537-571.

Montero, I., I. Ruiz-Perez, D. Martin-Baena, M. Talavera, V. Escriba-Aguir and C. Vives-Cases (2011). "Violence against women from different relationship contexts and health care utilization in Spain." Womens Health Issues 21(5): 400-406.

Nybergh, L., C. Taft, V. Enander and G. Krantz (2013). "Self-reported exposure to intimate partner violence among women and men in Sweden: results from a population-based survey." BMC Public Health 13(1): 845.

Parks, S. E., K. H. Kim, N. L. Day, M. A. Garza and C. A. Larkby (2011). "Lifetime self-reported victimization among low-income, urban women: the relationship between childhood maltreatment and adult violent victimization." J Interpers Violence 26(6): 1111-1128.

Porcerelli, J. H., R. Cogan, P. P. West, E. A. Rose, D. Lambrecht, K. E. Wilson, R. K. Severson and D. Karana (2003). "Violent victimization of women and men: physical and psychiatric symptoms." J Am Board Fam Pract 16(1): 32-39.

Renner, L. M. and S. D. Whitney (2012). "Risk factors for unidirectional and bidirectional intimate partner violence among young adults." Child Abuse Negl 36(1): 40-52.

Rich, C. L., C. A. Gidycz, J. B. Warkentin, C. Loh and P. Weiland (2005). "Child and adolescent abuse and subsequent victimization: a prospective study." Child Abuse Negl 29(12): 13731394.

Romito, P. and M. Grassi (2007). "Does violence affect one gender more than the other? The mental health impact of violence among male and female university students." Soc Sci Med 65(6): 1222-1234.

Romito, P., J. Molzan Turan and M. De Marchi (2005). "The impact of current and past interpersonal violence on women's mental health." Soc Sci Med 60: 1717-1727.

Scarpa, A. (2003). "Community violence exposure in young adults." Trauma Violence Abuse 4(3): 210-227.

Scott-Storey, K. (2011). "Cumulative abuse: do things add up? An evaluation of the conceptualization, operationalization, and methodological approaches in the study of the phenomenon of cumulative abuse." Trauma Violence Abuse 12(3): 135-150.

Stanko, E. A. (2006). "Theorizing about violence: observations from the Economic and Social Research Council's Violence Research Program." Violence Against Women 12(6): 543-555.

Swahnberg, K. (2011). "NorVold Abuse Questionnaire for men (m-NorAQ): validation of new measures of emotional, physical, and sexual abuse and abuse in health care in male patients." Gend Med 8(2): 69-79.

Swahnberg, K., J. Davidsson-Simmons, J. Hearn and B. Wijma (2012). "Men's experiences of emotional, physical, and sexual abuse and abuse in health care: A cross-sectional study of a Swedish random male population sample." Scand J Public Health 40(2): 191-202.

Swahnberg, K., J. Hearn and B. Wijma (2009). "Prevalence of perceived experiences of emotional, physical, sexual, and health care abuse in a Swedish male patient sample." Violence Vict 24(2): 265-279.

Swahnberg, K. and B. Wijma (2003). "The NorVold Abuse Questionnaire (NorAQ): Validation of new measures of emotional, physical, and sexual abuse, and abuse in the health care system among women." Eur J Public Health 13(4): 361-366.

Swahnberg, K., B. Wijma, B. Schei, M. Hilden, K. Irminger and G. B. Wingren (2004). "Are sociodemographic and regional and sample factors associated with prevalence of abuse?" Acta Obstet Gynecol Scand 83(3): 276-288.

Taylor, C. A., N. W. Boris, S. S. Heller, G. A. Clum, J. C. Rice and C. H. Zeanah (2008). "Cumulative experiences of violence among high-risk urban youth." J Interpers Violence 23(11): 16181635.

Tjaden, P. and N. Thoennes (2000). Full report on the prevalence, incidence and consequences of violence against women. Washington D.C. (USA), US Department of Justice. 
Tjaden, P. and N. Thoennes (2000). "Prevalence and consequences of Male-to-Female and Female-toMale Intimate Partner Violence as measured by the National Violence Against Women Survey." Violence Against Women 6(2): 142-161.

Whitfield, C. L., R. Anda, S. R. Dube and V. Felitti (2003). "Violent childhood experiences and the risk of intimate partner violence in adults." Journal of Interpersonal Violence 18(2): 166-185.

Widom, C. S., S. J. Czaja and M. A. Dutton (2008). "Childhood victimization and lifetime revictimization." Child Abuse Negl 32(8): 785-796.

Wijma, B., B. Schei, K. Swahnberg, M. Hilden, K. Offerdal, U. Pikarinen, K. Sidenius, T. Steingrimsdottir, H. Stoum and E. Halmesmaki (2003). "Emotional, physical, and sexual abuse in patients visiting gynaecology clinics: a Nordic cross-sectional study." Lancet 361(9375): 2107-2113. 
Table 1. Questions about violent victimization in NorAQ

\section{EMOTIONAL VIOLENCE}

Mild Have you experienced anybody systematically and for a longer period trying to repress, degrade, or humiliate you?

Moderate Have you experienced anybody systematically and by threat or force trying to limit your contact with others or totally control what you may and may not do?

Severe Have you experienced living in fear because somebody systematically and for a longer period threatened you or somebody close to you?

\section{PHYSICAL VIOLENCE}

Moderate Have you experienced anybody hitting you with his/her fist(s) or with a hard object, kicking you, pushing you violently, giving you a beating, thrashing you, or doing anything similar to you?

Severe Have you experienced anybody threatening your life by, for instance, trying to strangle you, showing a weapon or knife, or by any other similar act?

\begin{tabular}{l}
\hline SEXUAL VIOLENCE \\
\hline Mild \\
in a "sexual way" or forced you to touch other parts of his or her body in a \\
"sexual way"?
\end{tabular}

Mild/ Have you in any other way been sexually humiliated; for example, by being

Sexual forced to watch a pornographic movie or similar against your will, forced to

humiliation participate in a pornographic movie or similar, forced to show your body naked, or forced to watch when somebody else showed his/her body naked?

Moderate Has anybody against your will touched your genitals, used your body to satisfy him/herself sexually, or forced you to touch anybody else's genitals?

Severe Has anybody against your will put his penis into your vagina, mouth or rectum abuse or tried any of this, or put in or tried to put an object or other part of the body into your vagina, mouth or rectum?

Note: The word "vagina" was omitted from the male version of the questionnaire. 
Table 2. Background characteristics

\begin{tabular}{|c|c|c|c|c|c|c|c|c|}
\hline & \multicolumn{4}{|c|}{ Population sample } & \multicolumn{4}{|c|}{ Clinical sample } \\
\hline & \multicolumn{2}{|c|}{ Women n=2924 } & \multicolumn{2}{|c|}{ Men n=1168 } & \multicolumn{2}{|c|}{ Women $n=2439$} & \multicolumn{2}{|c|}{ Men n=1767 } \\
\hline & $\mathrm{n}$ & $\%$ & $\mathrm{n}$ & $\%$ & $\mathrm{n}$ & $\%$ & $\mathrm{n}$ & $\%$ \\
\hline Age group & $\mathrm{p}<0.01$ & & & & $\mathrm{p}<0.0$ & & & \\
\hline$\leq 29$ & 253 & 21.9 & 594 & 20.5 & 390 & 16.1 & 115 & 6.5 \\
\hline $30-39$ & 241 & 20.9 & 562 & 19.4 & 523 & 21.5 & 143 & 8.1 \\
\hline $40-49$ & 284 & 24.6 & 648 & 22.4 & 489 & 20.1 & 174 & 9.9 \\
\hline $50-59$ & 294 & 25.5 & 705 & 24.4 & 599 & 24.7 & 317 & 18.0 \\
\hline$\geq 60$ & 83 & 7.2 & 385 & 13.3 & 428 & 17.6 & 1012 & 57.5 \\
\hline Civil status & $\mathrm{p}<0.01$ & & & & $\mathrm{p}<0.0$ & & & \\
\hline Single & 225 & 19.4 & 839 & 29.2 & 374 & 15.5 & 357 & 20.3 \\
\hline Partner & 932 & 80.6 & 2035 & 70.8 & 2045 & 84.5 & 1401 & 79.7 \\
\hline Education & $\mathrm{p}=0.3$ & & & & $\mathrm{p}<0 . \mathrm{C}$ & & & \\
\hline$\leq 12$ years & 646 & 55.5 & 1668 & 57.4 & 1526 & 62.9 & 1199 & 68.2 \\
\hline$\geq 13$ years & 517 & 44.5 & 1237 & 42.6 & 901 & 37.1 & 558 & 31.8 \\
\hline Occupation & $\mathrm{p}<0.01$ & & & & $\mathrm{p}<0 . \mathrm{C}$ & & & \\
\hline Employed & 807 & 70.7 & 2309 & 80.0 & 1599 & 67.7 & 825 & 46.9 \\
\hline Parental leave & 40 & 3.5 & 7 & 0.2 & 91 & 3.9 & 4 & 0.2 \\
\hline Unemployed & 59 & 5.2 & 93 & 3.2 & 89 & 3.8 & 33 & 1.9 \\
\hline Student & 130 & 11.4 & 283 & 9.8 & 157 & 6.6 & 57 & 3.2 \\
\hline Retired, sick & 106 & 9.3 & 196 & 6.8 & 427 & 18.1 & 840 & 47.8 \\
\hline leave, welfare & & & & & & & & \\
\hline
\end{tabular}

Note: Internal drop out $n=24-84$ (0.6-2\%). $P$ values stand for test of differences in the distribution of background characteristics between the sexes in each sample. 
Figure 1. Venn diagrams illustrating how different kinds of violent experiences and categories of perpetrator overlap

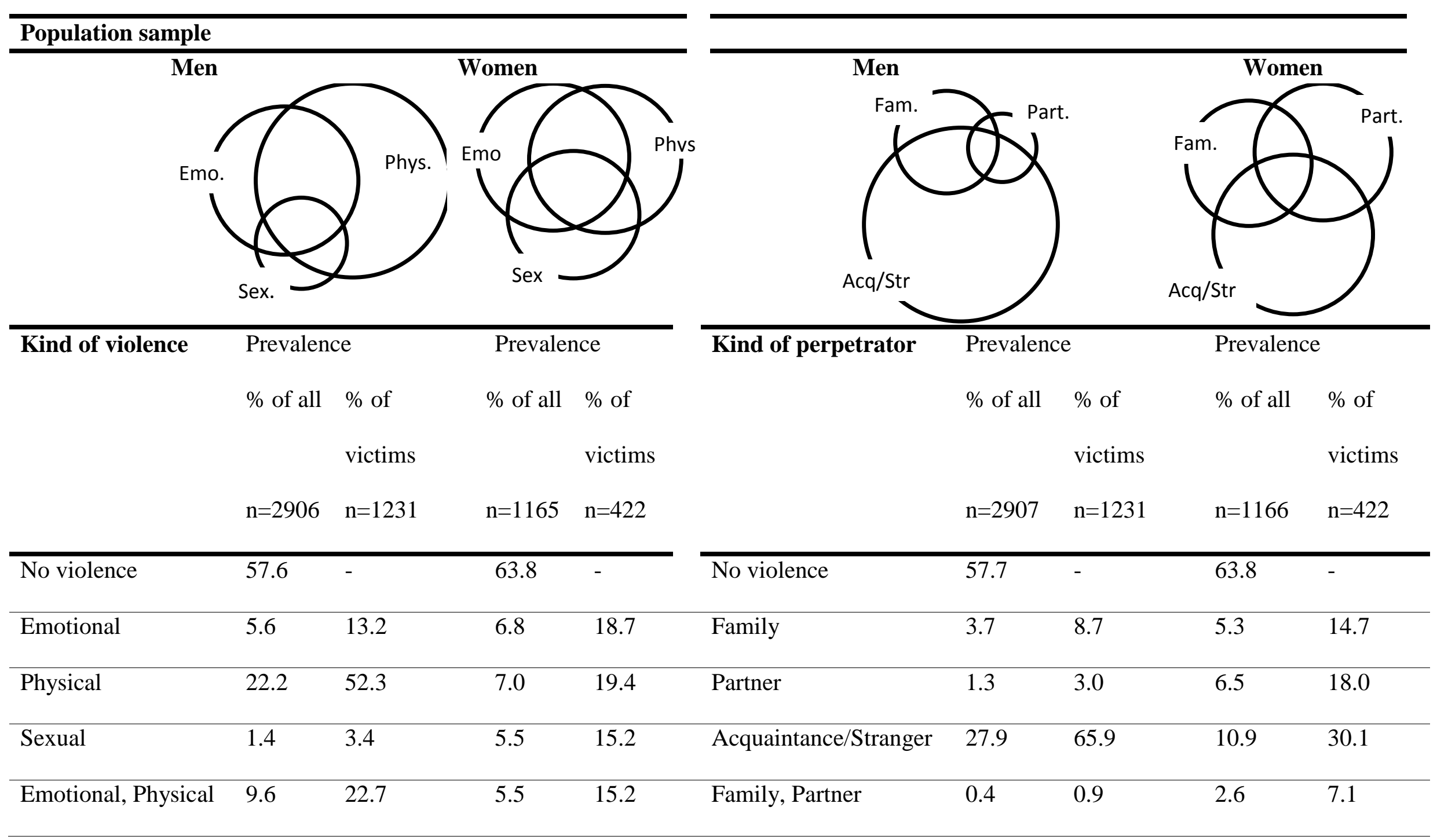




\begin{tabular}{|c|c|c|c|c|c|c|c|c|c|}
\hline Emotional, Sexual & 0.5 & 1.1 & 3.0 & 8.3 & $\begin{array}{l}\text { Family, } \\
\text { Acquaintance/St }\end{array}$ & 6.1 & 14.4 & 4.2 & 11.6 \\
\hline Physical, Sexual & 0.9 & 2.0 & 1.7 & 4.7 & $\begin{array}{l}\text { Partner, } \\
\text { Acquaintance/St }\end{array}$ & 1.8 & 4.2 & 3.9 & 10.7 \\
\hline Emotional, Physical, & 2.2 & 5.1 & 6.7 & 18.5 & Family, Partner, & 1.2 & 2.9 & 2.8 & 7.8 \\
\hline
\end{tabular}

Kind of violence




\begin{tabular}{|c|c|c|c|c|c|c|c|c|c|}
\hline No violence & 65.4 & - & 67.0 & - & No violence & 65.5 & - & 67.1 & - \\
\hline Emotional & 4.3 & 12.5 & 4.6 & 14.0 & Family & 4.6 & 13.3 & 5.3 & 16.0 \\
\hline Physical & 19.5 & 56.4 & 7.2 & 21.9 & Partner & 0.8 & 2.3 & 7.5 & 22.9 \\
\hline Sexual & 0.8 & 2.3 & 5.5 & 16.6 & Acquaintance/Stranger & 21.2 & 61.5 & 9.3 & 28.2 \\
\hline Emotional, Physical & 7.1 & 20.4 & 4.7 & 14.4 & Family, Partner & 0.2 & 0.7 & 1.9 & 5.8 \\
\hline Emotional, Sexual & 0.5 & 1.5 & 2.6 & 7.8 & $\begin{array}{l}\text { Family, } \\
\text { Acquaintance/Stranger }\end{array}$ & 6.2 & 17.9 & 3.0 & 9.1 \\
\hline Physical, Sexual & 1.5 & 4.3 & 2.3 & 7.0 & $\begin{array}{l}\text { Partner, } \\
\text { Acquaintance/Stranger }\end{array}$ & 0.9 & 2.6 & 3.5 & 10.5 \\
\hline $\begin{array}{l}\text { Emotional, Physical, } \\
\text { Sexual }\end{array}$ & 0.9 & 2.6 & 6.1 & 18.4 & $\begin{array}{l}\text { Family, Partner, } \\
\text { Acquaintance/Stranger }\end{array}$ & 0.6 & 1.6 & 2.5 & 7.5 \\
\hline
\end{tabular}

Note: Note: Each of the Venn diagrams is proportional in itself but not in relation to each other. Missing cases population sample: kind of

abuse: 21 (0.5\%), kind of perpetrator: 19 (0.5\%); clinical sample: kind of abuse 13 (0.3\%), kind of perpetrator $28(0.7 \%)$. All differences seen between the sexes regarding prevalence rates are significant ( $<<0.01)$. The Venn diagrams have been constructed using a method developed by

Chow and Rodgers (Chow and Rodgers. 2005). 
Figure 2. The co-occurrence of violent behavior by kind of perpetrator for men and women in the population and clinical sample

\section{Population sample: Men}

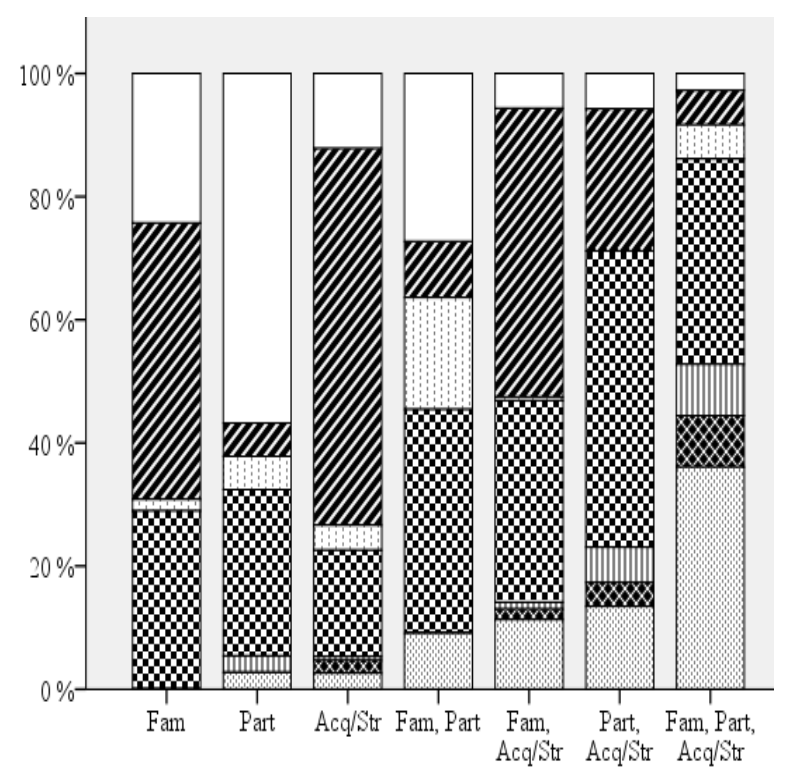

Clinical sample : Men

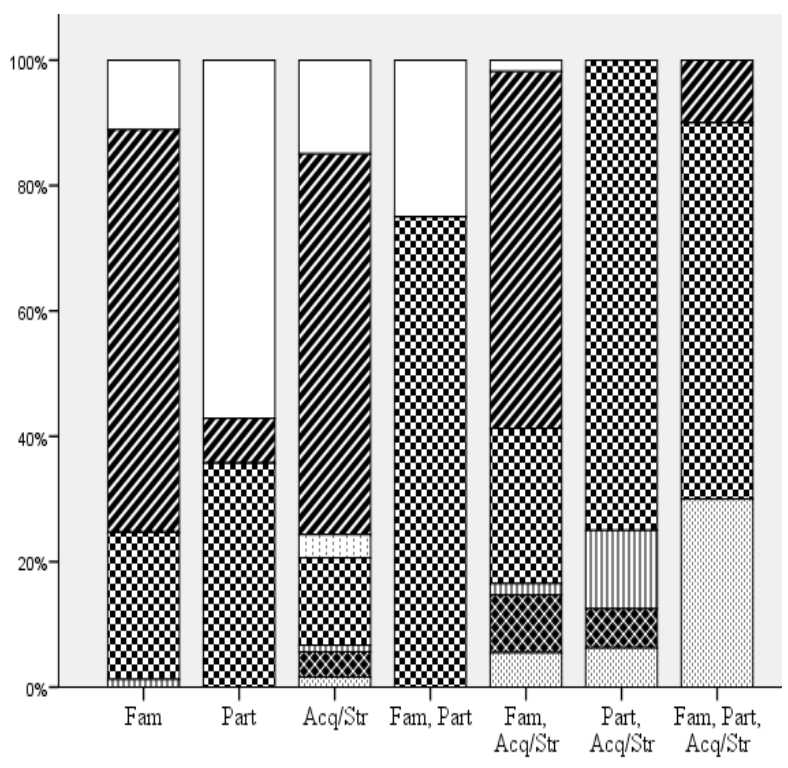

Women

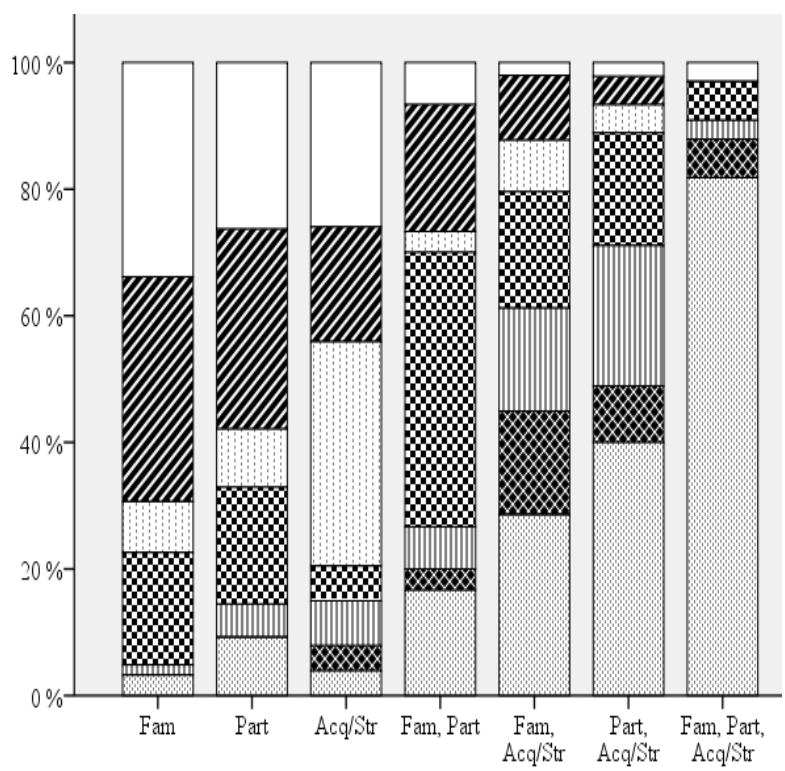

Women

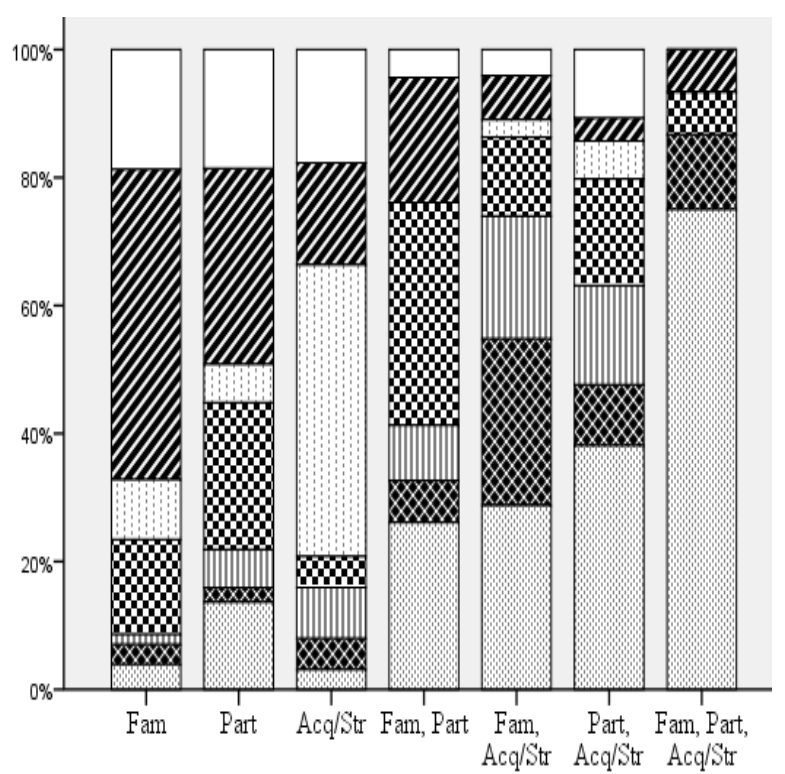

Note: Abbrevations: Fam $=$ Family perpetrator, Part $=$ Partner perpetrator Acq $/$ Str = Acquaintance $/$ Stranger perpetrator

Emotional
Physical
Sexual
Emotional, Physical
Emotional, Sexual
Physical, Sexual
Emotional, Physical, Sexual


Table 3. Odds of reporting violence by each kind of perpetrator depending on experiences of victimization by the other kinds of perpetrators

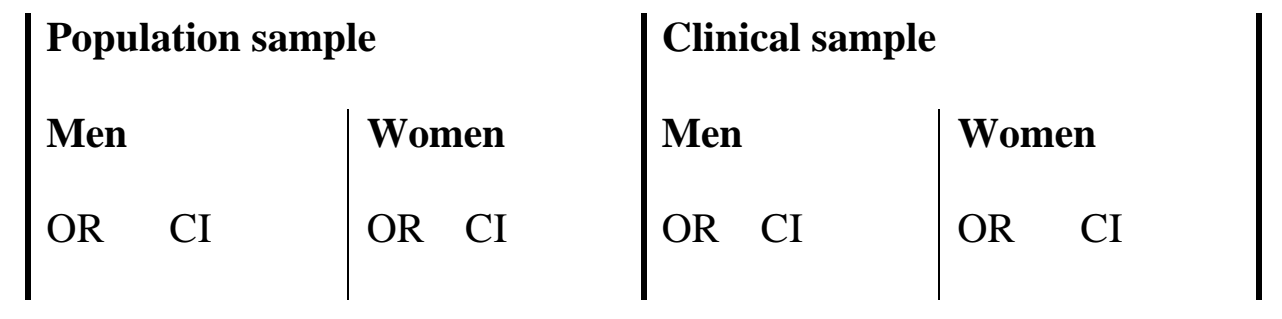

Odds of reporting violence by a partner

\begin{tabular}{l|cc|cc|cc||cc|} 
No other perp & 1.0 & & 1.0 & & 1.0 & & 1.0 & \\
Fam & 5.1 & $2.5-10.5$ & 4.4 & $2.6-7.3$ & 4.8 & $1.5-15.3$ & 2.8 & $1.9-4.1$ \\
Acq/Str & 3.0 & $1.9-4.7$ & 3.3 & $2.1-5.0$ & 2.8 & $1.3-5.9$ & 3.1 & $2.3-4.2$ \\
Fam + acq/str & 9.7 & $5.9-16.1$ & 6.1 & $3.6-10.2$ & 6.3 & $2.6-15.2$ & 6.8 & $4.6-10.2$
\end{tabular}

Odds of reporting violence by a family member

\begin{tabular}{l|cc|cc|cc|cc|} 
No other perp & 1.0 & & 1.0 & & 1.0 & & 1.0 & \\
Part & 5.2 & $2.5-10.8$ & 4.4 & $2.6-7.3$ & 4.5 & $1.4-14.2$ & 2.9 & $2.0-4.3$ \\
Acq/str & 3.7 & $2.8-4.8$ & 4.3 & $2.8-6.7$ & 4.3 & $3.1-5.9$ & 4.0 & $2.9-5.5$ \\
Part + acq/str & 11.6 & $7.1-18.8$ & 8.0 & $4.7-13.8$ & 9.5 & $4.0-22.5$ & 7.8 & $5.3-11.6$
\end{tabular}

Odds of reporting violence by an acquaintance/stranger

\begin{tabular}{l|cc|cc|cc|cc|} 
No other perp & 1.0 & & 1.0 & & 1.0 & & 1.0 & \\
Family & 3.7 & $2.8-4.8$ & 4.2 & $2.7-6.6$ & 4.2 & $3.1-5.9$ & 4.0 & $2.9-5.5$ \\
Part & 3.1 & $2.0-4.9$ & 3.2 & $2.1-4.9$ & 2.7 & $1.3-5.9$ & 3.2 & $2.3-4.3$ \\
Fam + part & 6.4 & $3.2-12.8$ & 6.1 & $3.5-10.7$ & 5.9 & $1.8-19.5$ & 8.5 & $5.6-13.1$
\end{tabular}

Note: $O R=$ Odds ratio. $C I=95 \%$ confidence interval. All models were adjusted for age, education, occupation, and civil status. Abbrevations: Fam = Family perpetrator, Part $=$ Partner perpetrator Acq / Str = Acquaintance / Stranger perpetrator 